\title{
Fourth ventricular meningioma in an adult: Case report and review of the literature
}

\author{
Rajendra Shrestha, Zhang Yue-Kang, You Chao \\ Department of Neurosurgery, West China Hospital, Sichuan University, 37 Guo Xue Xiang, Wuhou District, Chengdu, China
}

\section{A B S T R A C T}

Meningiomas are one of the most common clinical entities in everyday neurosurgical practice. Most meningiomas are extra-axial dural-based lesions. They typically occur along intradural venous sinuses, at the confluences of multiple cranial sutures and also others sites where arachnoid granulations and arachnoid cell rests occur. Most of these tumors also do occur within the lateral ventricles than third ventricle but they are exceptional in fourth ventricle thought to arise from the choroid plexus without dural attachment. Here we present two cases of fourth ventricle meningiomas.

Key words: Fourth ventricle, meningioma, surgery

\section{INTRODUCTION}

Meingiomas are the most common nonglial primary brain tumor and the most common intracranial extraaxial neoplasm. They account for $14.3 \%-19 \%$ of all primary intracranial tumors. ${ }^{[1]}$ Intraventricular meningiomas are rare, representing $0.5 \%-3 \%$ of all intracranial meningiomas. Among them, it finds $80 \%$ in lateral ventricles, $15 \%$ in the third ventricle, and $5 \%$ in the fourth ventricle. ${ }^{[2]}$ They are basically adult tumors and are roughly twice as common in women as men (1.8:1). Although there are numerous case reports of meningioma in the literature, but fourth ventricles meningiomas are rare. Here, we reviewed the literature with fourth ventricle meningioma.

\section{CASE REPORTS}

Case 1

A 56-year-old male was presented with unsteady gait for 6 months and history of progressive headache and dizziness for 1 year. Pain was not serious initially, but it was radiated from right scalp into right face and eye,

\begin{tabular}{|l|l|}
\hline \multicolumn{2}{|c|}{ Access this article online } \\
\hline Quick Response Code: & Website: \\
\hline & www.ijns.in \\
\cline { 2 - 2 } & \\
\hline
\end{tabular}

accompanied with neck stiffness, double vision. The physical examination disclosed obesity, and the neurologic evaluation did not reveal any impairment. A magnetic resonance imagines (MRI) scan showed an enhancing well-defined $(3.7 \times 3.3 \times 3.3)$ lesion within the fourth ventricle with mild hydrocephalus [Figures $1 \mathrm{a}$ and $\mathrm{b}$ ]. A midline posterior fossa craniotomy was performed, and a microsurgical total resection was achieved. No attachment to the fourth ventricle wall was clearly identified. The postoperative course was uneventful. No adjuvant therapy was done. A postoperative MRI revealed no evidence of residual tumor [Figures $2 \mathrm{a}$ and $\mathrm{b}$ ].

\section{Case 2}

A 62-year old right-handed man presented with headache, dizziness for one year. It was aggravated with unsteady gait for 6 months. The physical examination disclosed obesity, and the neurologic evaluation revealed cerebellar function test abnormality. An MRI scan showed an enhancing mass lesion in the fourth ventricle [Figures $3 \mathrm{a}$ and $\mathrm{b}$ ]. A midline posterior fossa craniotomy was achieved and tumor was resected in total. Post operatively patient was managed in the intensive care unit. Histopathological examination confirmed fourth ventricle fibroblastic meningioma [Figure 4]. The postoperative period was uneventful.

\section{DISCUSSION}

Even, meningioma is a common tumor of the central nervous system in adults; fourth ventricle meningioma (FVM) was first described and surgically removed

Address for correspondence: Prof. You Chao,

Department of Neurosurgery, West China Hospital, Sichuan University, 37 Guo Xue Xiang, Wuhou District, Chengdu 610041, China.

E-mail: youchaowch@gmail.com 

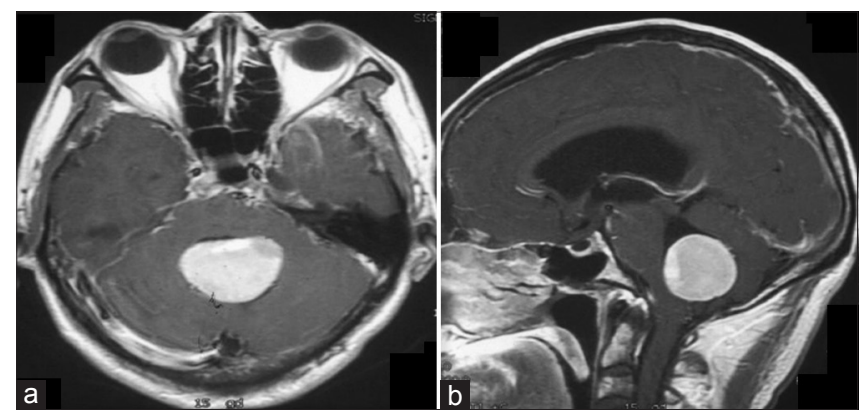

Figure 1: Case 1 (a) axial and (b) sagittal T1-weighted contrast-enhanced MRI show an intense enhancement of a well-defined rounded mass in the fourth ventricle with homogenous signal

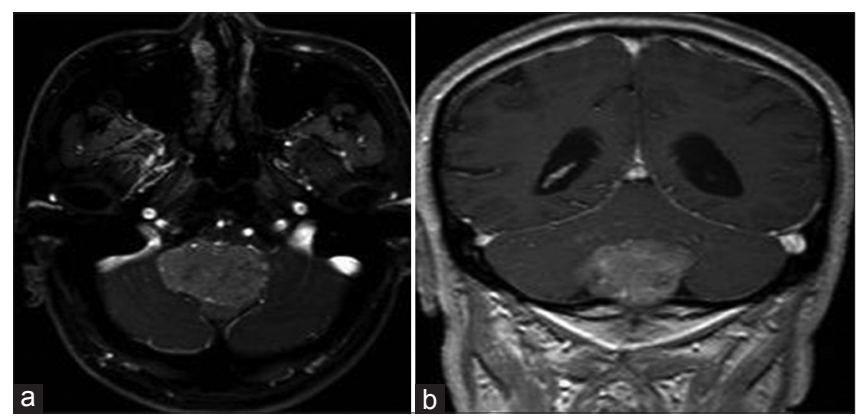

Figure 3: Case 2 (a) axial and (b) coronal T1-weighted contrast-enhanced MRI show an intense enhancement of rounded mass in the fourth ventricle with heterogeneous intermediate signal

by Sachs in $1983 . .^{[3-9]}$ Intraventricular meningiomas (IVM) mainly occurs in the lateral ventricles but rarely located strictly within the fourth ventricle. It sometime remains asymptomatic throughout the patient's life. In 1963, Abraham and chandy ${ }^{[10]}$ and later Hoffman et al. classified posterior fossa meningiomas without dural attachment as Type I: meningiomas that arise from the choroidal plexus of the fourth ventricle and locate entirely inside ventricular cavity, Type II: meningiomas that arise from the inferior tela choroidea and partially located cerebellar hemisphere, and Type III: meningiomas located within the cisterna magna but not implanted in the duramater. Our both cases represent to the Type I of this classification. To our best knowledge, 30 patients were found to have fourth ventricle meningiomas in the literatures $^{[3-10]}[$ Table 1]. Among these 30 patients, 7 were younger than 20 , and 10 patients over 50 years old. The mean age was 42 years, with a range of $14-72$ years. Including our cases, $61 \%$ of patients were female (17) and $40 \%$ were male (11).

There is no specific clinical feature to the intraventricular located tumor. Headache is most common presentation with raised intracranial pressure. Sometime, intensity of headache may increase with postural change as pendulated tumor leads to CSF flow obstruction. There may be mild papilledema and cerebellar signs such as

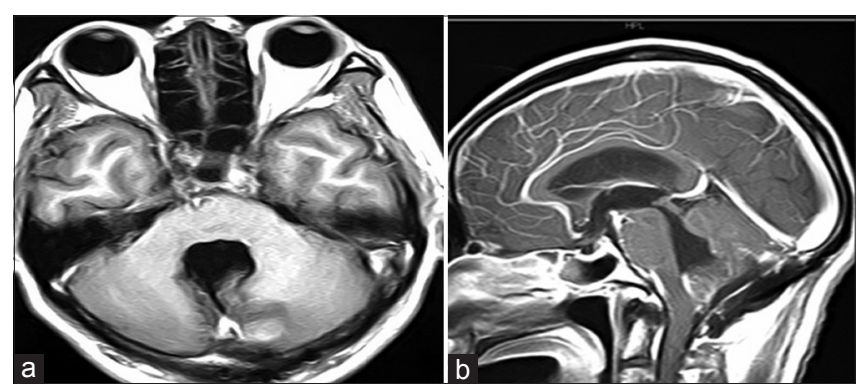

Figure 2: Case 1-Postoperative (a) axial and (b) sagittal T1-weighted contrast enhanced MRI images show fourth ventricle without any sign of tumor residual and recurrence

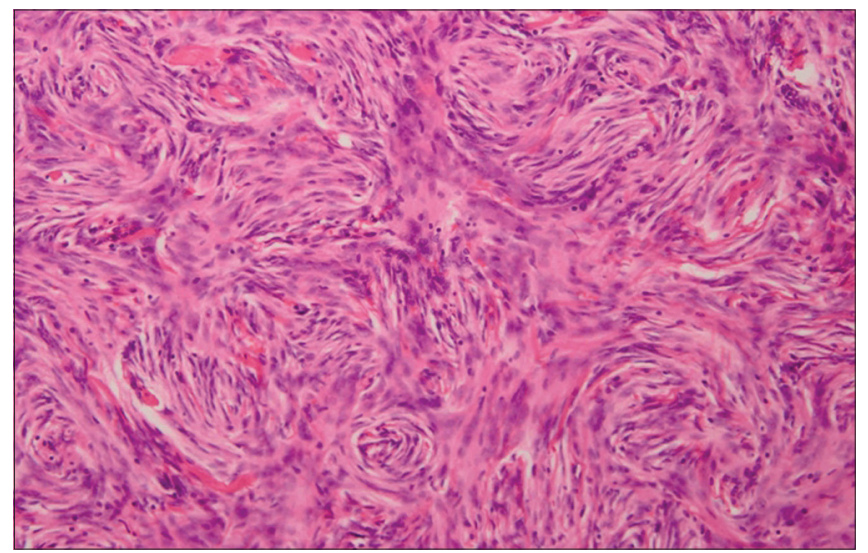

Figure 4: Case 2-Histopathological examination showing a well differentiated meningioma with lobulated pattern, whorls and no signs of anaplasia (Haemotoxylin and Eosin $\times 200$ )

ataxia and dysmetria, progressive cognitive changes, early memory loss. Other features including seizures, visual field defects, sensory impairment and motor weakness are attributed to mass effect on surrounding structures. The clinical symptoms are usually progressive with duration of time. ${ }^{[3-7]}$

The differential diagnosis for meningioma in fourth ventricle includes arachnoid cysts, epidermoid cysts, dermoid cysts, medulloblastoma, and astrocytoma. It is difficult to differentiate because of the rarity of the tumor and its atypical radiological feature. However, combination of heterogeneous enhancement on MRI, anatomical detail and ill-defined margin with tumor extent, may be useful clues for the prospective diagnosis of meningioma in this location. On CT scan, an arachnoid cyst appears as a smooth, noncalcified, extra-axial, nonenhancing lesion with a density identical to that of CSF. On MRI, the lesion appears sharply demarcated and extra-axial; it displaces or deforms adjacent brain. The cyst has no internal architecture and does not demonstrate significant contrast enhancement. A dermoid cyst appears on CT scan as a clearly demarcated, round, hypodense lesion with foci of calcification. The signal on MRI is determined by the 


\begin{tabular}{|c|c|c|c|c|c|c|}
\hline Cases & Authors & Year & Sex & Age & Pathology & Treatment approach \\
\hline 1 & Sachs et al. & 1938 & $\mathrm{~F}$ & 38 & Fibroblastic & Total resection \\
\hline 2 & Schaerer and Woolsey et al. & 1950 & $\mathrm{~F}$ & 42 & Fibroblastic & Total resection \\
\hline 3 & Vogel and Stevenson et al. & 1950 & M & 65 & Meningothelial & Autopsy finding \\
\hline 4 & Haas and Ritter et al. & 1954 & M & 41 & Fibroblastic & Autopsy finding \\
\hline 5 & Hoffman et al. & 1970 & $\mathrm{~F}$ & 44 & Transitional & Total resection \\
\hline 6 & Hoffman et al. & 1970 & $\mathrm{~F}$ & 42 & Transitional & Total resection \\
\hline 7 & Rodriquez-Carbajal et al. & 1974 & $\mathrm{~F}$ & 32 & Meningothelial & Total resection \\
\hline 8 & Rodriquez-Carbajal et al. & 1974 & $\mathrm{~F}$ & 49 & Meningothelial & Sub-total \\
\hline 9 & Gokalp et al. & 1981 & $\mathrm{~F}$ & 30 & Psammomatous & Total resection \\
\hline 10 & Giromini et al. & 1981 & $\mathrm{~F}$ & 14 & Endotheliomatous & Total resection \\
\hline 11 & Tsuboi et al. & 1983 & $\mathrm{~F}$ & 30 & Fibroblastic & Total resection \\
\hline 12 & Nagata et al. & 1983 & $\mathrm{~F}$ & 52 & Fibroblastic & Total resection \\
\hline 13 & Matsumara et al. & 1988 & M & 62 & Fibroblastic & Total resection \\
\hline 14 & Ceylan et al. & 1992 & $M$ & 48 & Meningothelial & Total resection \\
\hline 15 & Lima-de-Freitas et al. & 1994 & $\mathrm{~F}$ & 32 & Meningothelial & Total resection \\
\hline 16 & Iseda et al. & 1997 & $\mathrm{~F}$ & 47 & Transitional & Total resection \\
\hline 17 & Cummings et al. & 1999 & $M$ & 72 & Fibroblastic & Total resection \\
\hline 18 & Chaskis et al. & 2001 & $M$ & 72 & Fibroblastic & Total resection \\
\hline 19 & Akimoto et al. & 2001 & $\mathrm{~F}$ & 72 & Transitional & Total resection \\
\hline 20 & Carlotti et al. & 2003 & $F$ & 28 & Clear cell & Total resection \\
\hline 21 & Carlotti et al. & 2003 & $\mathrm{~F}$ & 23 & Clear Cell & Total resection \\
\hline 22 & Makhmudov et al. & 2003 & $\mathrm{~F}$ & NA & NA & Total resection \\
\hline 23 & Bhatoe et al. & 2006 & NA & NA & Fibroblastic & Total resection \\
\hline 24 & Bhatoe et al. & 2006 & NA & NA & Meningothelial & Total resection \\
\hline 25 & Bertalanffy et al. & 2006 & NA & NA & NA & Total resection \\
\hline 26 & Liu et al. & 2006 & NA & NA & NA & Total resection \\
\hline 27 & Epsari et al. & 2006 & $\mathrm{~F}$ & 20 & Chordoid & Total resection \\
\hline 28 & Alver et al & 2009 & $M$ & 61 & Fibroblastic & Total resection \\
\hline 29 & Wind et al. & 2010 & M & 23 & chordoid & Total resection \\
\hline 30 & Burgan et al. & 2010 & M & 14 & Clear cell & Total resection \\
\hline 31 & Our case & 2011 & M & 56 & Fibroblastic & Total resection \\
\hline 32 & Our case & 2011 & $\mathrm{M}$ & 62 & Fibroblastic & Total resection \\
\hline
\end{tabular}

NA - Not available

relative amount of hair follicles, sebum and water in individual cysts. Cysts typically have high signal intensity on T1-weighted sequences due to their lipid content, and heterogeneous signal intensity on T2-weighted sequences due to their mixed composition. Their capsule is generally thicker than those of epidermoid cysts and often contains calcifications, hair, and even teeth. Diagnosis of epidermoid tumor through CT alone is difficult. On T1-weighted MRI, epidermoid cysts generally appear hypointense, whereas T2-weighted MRI demonstrates a hyperintense lesion. However, this presentation has been shown to be somewhat variable depending upon the cystic contents. Typically, cholesterol inclusions are in a solid state and appear hypointense on T1-weighted MRI. Although CT is superior to MRI in detecting associated intratumoral calcifications, MRI is more sensitive in the detection of medulloblastomas and the determination of the relationship of the tumor to central nervous system structures, especially the brain stem. On MRI, medulloblastomas usually have a T2 signal similar to or lower than the cerebellar cortex. It will have cystic or necrotic areas in up to $40 \%$ of cases and over $90 \%$ of tumors will have some degree of contrast enhancement, usually homogeneous. ${ }^{[11]}$ Choroid plexus papillomas (CPP) are usually isodense or hyperdense intraventricular masses on unenhanced CT scans. The uncalcified portions of CPPs appear isointense or hypointense to normal brain parenchyma on $\mathrm{T} 1$-weighted images and hyperintense on $\mathrm{T} 2$-weighted images. Contrast enhancement on MRI tends to be uniform and intense, and flow voids are common. Fourth ventricular CPPs will appear markedly calcified, whereas ependymomas will not. ${ }^{[12]}$ Hemangioblastomas has four parts: simple cystic, macro cystic, solid and microcystic solid. On CT, the cyst fluid has a higher density than that of CSF. Moreover, solid tumors and peripheral mural nodules of cystic tumors are isodense with brain tissue and show marked homogenous contrast enhancement. 
The solid part of the tumor is usually hypointense or isointense on a T1-weighted MRI. The solid part shows diffuse enhancement with contrast medium and the cystic part is hyperintense on T2-weighted images. ${ }^{[13]}$ However, the diagnosis can be suspected through CT or MRI scan, it can only be confirmed by histopathogical examination.

FVMs may be managed conservatively or treated with surgery or radiosurgery. Radiosurgery may be recommended for patients who are not candidates for general anesthesia or who refuse surgical intervention, although the intraventricular location poses distinct limitations to this technique. It is an effective form of treatment with control rates ranging from $85 \%$ to $98 \%{ }^{[14,15]}$ However, this is only appropriate for tumors with a size of $1.5-2 \mathrm{~cm}$. Some authors mention that it is useful mainly in recurrences or residual tumors since most of the primary IVMs attain a large size before they are detected. ${ }^{[2]}$ The goal of surgery is to obtain complete surgical resection of these relatively benign tumors to provide cure without postoperative deficits. Surgery is challenging as these lesions are often large, deeply situated, often in close proximity to important vascular structures. Fourth ventricular tumors are supplied by the PICA which may be accessed immediately following vermian splitting on either side of the brain stem. Intraoperative neurophysiological monitoring is an important for the FVMs surgery. This monitoring helps prevent operative injury of cranial nerves and the brain stem. It also helps decrease postoperative complications. Electromyographic monitoring of the vagal, accessory, and hypoglossal nerves should be done ipsilateral to the lesion, or bilaterally when necessary. In our both cases, we resected under microscopic and intraoperative neurophysiological monitoring. Reviewing the cases in the literature, including our cases, total resection was achieved in all except only one case (case-8 in Table 1). Total excision should be the aim as partial tumor resection may cause the tumor to bleed at a later date; sequestration of CSF may increase the chances of herniation, and the well-defined tumor-ependymal plane is usually lost during the second surgery. The wide range of mortality during surgery for FVMs reported in the literature, ${ }^{[3-9]}$ illustrates the vital role played by surgical experience and a thorough knowledge of the anatomy in excising these lesions. Most FVMs have a benign pathology, and surgical cure is expected. Complete excision was achieved in all patients in our series, without evidence of recurrence to date.

\section{CONCLUSION}

In contrast to posterior fossa meningiomas lying completely within the fourth ventricle, the total resection of purely intraventricular meningiomas can be obtained successfully with low operative risk and an excellent outcome under microscopic and intraoperative neurophysiological monitoring.

\section{REFERENCES}

1. Greenberg MS. Handbook of Neurosurgery: Meningiomas; $7^{\text {th }}$ ed. New York: Thieme; 2010. p. 613.

2. Lyngdoh BT, Giri PJ, Behari S, Banerji D, Chhabra DK, Jain VK. Intraventricular meningiomas: A surgical challenge. J Clin Neurosci 2007;14:442-8.

3. Chaskis C, Buisseret T, Michotte A, D'Haens J. Meningioma of the fourth ventricle presenting with intermittent behaviour disorders: a case report and review of the literature. J Clin Neurosci 2001;8:59-62.

4. Cantore G, Ciappetta P, Delfini R, Raco A. Meningiomas of the posterior cranial fossa without dural attachment. Surg Neurol 1986;25:127-30.

5. Delfini R, Capone R, Ciappetta P, Domenicucci M. Meningioma of the fourth ventricle: A case report. Neurosurg Rev 1992;15:147-9.

6. Alver I, Abuzayed B, Kafadar AM, Muhammedrezai S, Sanus GZ, Akar Z.: Primary fourth ventricular meningioma: Case report and review of the literature. Turk Neurosurg 2011;21:249-53.

7. Wind JJ, Jones RV, Roberti F. Fourth ventricular chordoid meningioma. J Clin Neurosci 2010;17:1301-3.

8. Burgan OT, Bahl A, Critcher V, Zaki HS, McMullan PJ, Sinha S. Clear cell meningioma of the fourth ventricle in a child: A case report and literature review. Pediatr Neurosurg 2010;46:462-5.

9. Tsuboi K, Nose T, Maki Y. Meningioma of the fourth ventricle: A case report. Neurosurgery 1983;13:163-6.

10. Abraham J, Chandy J. Meningiomas of the posterior fossa without dural attachment: A case report. J Neurosurg 1963;20:177-9.

11. Packer RJ. Childhood medulloblastoma: progress and future challenges. Brain Dev 1999;21:75-81.

12. Shin JH, Lee HK, Jeong AK, Park SH, Choi CG, Suh DC. Choroid plexus papilloma in the posterior cranial fossa MR, CT, and angiographic findings. Clin Imaging 2001; 25:154-62.

13. Koeller KK, Sandberg GD. From the archives of the AFIP. Cerebral intraventricular neoplasms: Radiologic-pathologic correlation. Radiographics 2002; 22:1473-505.

14. Lee JY, Niranjan A, Mclnerney J, Kondziolka D, Flickinger JC, Lunsford LD. Stereotactic radiosurgery providing long-term tumor control of cavernous sinus meningiomas. J Neurosurg 2002; 97:65-72.

15. Pollock BE, Stafford SL, Utter A,Giannini C, Schreiner SA. Stereotactic radiosurgery provides equivalent tumor control to simpsons grade 1 resection for patients with small- to-medium-sized meningiomas. Int J Radiat Oncol Biol Phys 2003; 55: 1000-5.

How to cite this article: Shrestha R, Yue.Kang Z, Chao Y. Fourth ventricular meningioma in an adult: Case report and review of the literature. Indian J Neurosurg 2012;1:161-4.

Source of Support: Nil, Conflict of Interest: None declared. 